\title{
LOS COLEGIOS DIFERENCIADOS POR SEXO EN ESTADOS UNIDOS: CONSTITUCIONALIDAD Y ACTUALIDAD DE UNA TENDENCIA IMPARABLE
}

MARÍA CALVO CHARRO 
SUMARIO

I. INTRODUCCIÓN. II. REFERENCIA HISTÓRICA Y ACTUALIDAD DE LA EDUCACIÓN SINGLE-SEX EN EE.UU. III. CONSTITUCIONALIDAD Y LEGALIDAD DE LA EDUCACIÓN SINGLE-SEX. 1. Los colegios single-sex ¿discriminan por razón de sexo? La enmienda XIV a la Constitución de los EEUU. «Equal protection clause». a) Separación por raza en las escuelas públicas. b) Separación por sexo en las escuelas públicas. 2. Legalidad de la educación single-sex. El Título IX y la No Child Bebind Act. IV. LA EDUCACIÓN DIFERENCIADA. UNA OPCIÓN DE LIBERTAD. V. OPOSICIÓN A LOS COLEGIOS DIFERENCIADOS. VI. CONCLUSIÓN. LIBERTAD DE ELECCIÓN DE CENTRO DOCENTE. THE RIGHT TO CHOOSE. 


\title{
LOS COLEGIOS DIFERENCIADOS POR SEXO EN ESTADOS UNIDOS: CONSTITUCIONALIDAD Y ACTUALIDAD DE UNA TENDENCIA IMPARABLE
}

\author{
MARÍA CALVO CHARRO \\ Profesora Titular de Derecho Administrativo \\ Universidad Carlos III
}

«Educate and inform the whole mass of the people... They are the only sure reliance for the preservation of our liberty".

Letter from Thomas Jefferson to James Madison, 1787

\section{INTRODUCCIÓN}

En los últimos años Estados Unidos ha experimentado el resurgir de la educación diferenciada por sexo con el apoyo de políticos de muy diferentes tendencias ${ }^{1}$,

${ }^{1}$ La lista de políticos resulta encabezada por el propio presidente de los EEUU, Barack Obama y su Secretario de Educación Arne Duncan. Destacan asimismo, tanto del partido republicano como demócrata, entre otros: la Senadora Hillary Clinton; Susan Estrich; Senadora Kay Bailey Hutchison; Antolin Scalia; Senadora Susan Collins; Senador William Bennet; Senadora Barbara Mikulski. 
educadores $^{2}$, padres, ciertos sectores feministas ${ }^{3}$, así como asociaciones de defensa de los derechos de los afroamericanos y otras minorías ${ }^{4}$. Esta tendencia, lenta pero implacable entre los colegios públicos, ha generado un encendido debate en ámbitos académicos, legales y políticos.

La educación diferenciada por sexo (single-sex o también denominada same gender education) es probablemente uno de los asuntos más actuales en la lucha por la igualdad de oportunidades en el ámbito de la educación pública norteamericana, como muestra la amplia literatura académica, científica y divulgativa que constantemente sale a la luz al respecto ${ }^{5}$.

2 Benjamin Wright, 2003, elegido «Director del año» en Washington y autor del libro We can if we choose: «No soy científico, no soy jurista, soy un práctico de la docencia, y puedo asegurar que: ¡la separación por sexo en las aulas funciona! No es solo mi opinión... La realidad nos muestra que es la única forma de educar en la América actual, en la que tantos niños fracasan en la escuela».

Karen Stabiner, autora del libro All Girls: Single-Sex Education and Why It Matters «Los docentes en clases single-sex lo tienen muy claro: la igualdad es la meta, pero hay muchas vías para alcanzarla». M.Gurian, autor de Successful single sex classrooms; 2009: «El renacer de los colegios diferenciados es una de las innovaciones pedagógicas más poderosas e importantes de las últimas décadas, con un objetivo muy claro y definido: lograr la igualdad». Dr. F.Spielhagen, autor de Debating single sex education: separate an equal?: "Ya sea en el corazón de los Estados Unidos o en África, la educación diferenciada por sexo constituye la técnica docente más completa para acomodarse a las necesidades pedagógicas de cualquier alumno». D. Ravitch, autora de Why not a girls school?; New York Post, September 26, 1997, pág. 29: «En Estados Unidos tradicionalmente se ha defendido el pluralismo, la diversidad y la libertad de elección. Por ello, debería haber colegios mixtos para aquellos padres que lo deseen y colegios single-sex para aquellos otros que prefieran un ambiente libre de la presión y distracción que supone — especialmente en la adolescencia— la presencia constante del sexo opuesto».

${ }^{3}$ Sobre el feminismo que apoya la educación diferenciada, vid. SALOMONE, R. (2004). Feminist Voices in the Debate over Single-Sex Schooling: Finding Common Ground, 11, Mich J. Gender\& L. 63, 65. HOFF SOMMERS, C.(2000). The War Against Boys: How Misguided Feminism is Harming Our Young Men (Simon \& Schuster, New York).

${ }^{4} 100$ Black Men of America. Eagle Academy Foundation. Young Men Mentoring Institute. 100 Black Men of Obama Inc.

5 Vid., entre muchos otros, GURIAN, M., STEVENS, K. \& KING,K. (2008), Strategies for teaching boys and girls - elementary level, ed. Jossey-Bass, San Francisco, USA; Strategies for teaching boys and girls - secondary level, Ed. Jossey-Bass, San Francisco, USA. MACCOBY, E. (2003), The two sexes, growing up apart, coming together, ed. Harvard University Press. RHOADS, S.E. (2004), Taking Sex Differences Seriously, ed. Encounter Books. SALOMONE, R. (2003), Same, different, equal: rethinking single-sex schooling, ed. New Haven: Yale University Press. SAX, L. (2005), Why gender matters, ed. Doubleday. CLARK, C.S., «Education and Gender.» CQ Researcher 3 June 1994: 481-504. Web. 14 Nov. GUARISCO, C. (2010), Single-sex schools and gender roles:barrier or breakthrough?, May 19., 2010; GLAZER, S., «Gender and Learning.» CQ Researcher 20 May 2005: 457-467. Web. 18 Nov. 
Mientras para sus defensores supone una oportunidad para mejorar la educación, elevar el nivel académico y reducir los problemas disciplinarios y de abandono escolar; para sus detractores este modelo educativo discrimina por razón de sexo, revive los fantasmas del pasado relacionados con la segregación y pone en peligro las batallas ganadas por los movimientos feministas en favor de la igualdad entre los sexos ${ }^{6}$.

Pero la realidad es que no se trata de una vuelta al pasado. El modelo propuesto se opone de forma absoluta al tradicional y anticuado sistema escolar de roles separados, en el que se impartía una educación diferente a cada sexo mediante la separación física y curricular del proceso educativo de ambos grupos. La educación diferenciada moderna parte de la idea de que no hay asignados unos roles en la sociedad, sino que cada hombre y mujer debe tener las mismas oportunidades para poder optar con entera libertad por el papel que quieran desempeñar profesional y personalmente.

Su objetivo es la igualdad de oportunidades, garantizar una posibilidad real para niños y niñas de alcanzar los mismos objetivos y metas en lo profesional y lo personal. Una escuela que considera que las diferencias entre los sexos son siempre enriquecedoras y que lo que hay que eliminar son las discriminaciones ${ }^{7}$. Una escuela que tiene como objetivo la eliminación de estereotipos entre sexos, superando las desigualdades sociales y las jerarquías culturales entre hombres y mujeres ${ }^{8}$.

En estos momentos, los colegios públicos que ofrecen clases single-sex, a pesar de la fortísima presión ejercida en contra por la American Civil Liberties Union (ACLU), están creciendo exponencialmente como consecuencia de los excelentes resultados obtenidos ${ }^{9}$. La legislación norteamericana federal los motiva,

${ }^{6}$ Entre los detractores, vid. ZADKER, D. AND ZIMMERMAN, K. (2004), Single-Sex Schools: A Good Idea Gone Wrong?, CHRISTIAN SCI.MON., Apr. 8, at 9. http://www.sadker.org/ PDF/SingleSexSchools.pdf. KISTHARDT, E. (2007), Singling Them Out: The Influence of the Boy Crisis on the New Title IX Regulations, 22 WIS. WOMEN'S L.J. 313, 334.

7 GUARISCO,C., Single-sex schools and gender roles:barrier or breakthrough?, May 19., 2010.

8 Vid. al respecto, M.CALVO (2011), Educando para la igualdad, ed. EUNSA. DE LOS MOZOS, I. (2004), «Exigencias de la igualdad en la educación y legitimidad de especializaciones no discriminatorias», Persona y Derecho, 50. LOPEZ MUÑIZ, J.L. (2012) «Escolarización homogénea por razón de sexo y derecho fundamental a la educación en libertad», REDA, 154.

9 Entre los estudios que demuestran sus beneficios vid, CLARK, CH. S., «Education and Gender.» CQ Researcher 3 June 1994: 481-504. Web. 14 Nov. GLAZER, S., «Gender and Learning.» CQ Researcher 20 May: 457-467. Web. 18 Nov. 2011. MULLINS, A. (2005), «Single’ Sex Schools Can Improve Education.» CQ Researcher. 3 Aug. http://www.mercatornet.com/. Web. 19 Nov. NAT'L ASSOC. FOR SINGLE SEX PUBLIC EDUC., (2010), Single-Sex Schools /Schools with Single-Sex Classrooms/What's the Difference?, http://www.singlesexschools.org/schools-schools.htm 
incentiva y apoya, con ciertas condiciones relativas a garantizar la igualdad de oportunidades entre los sexos y la libertad de elección de los padres del modelo educativo que consideren apropiado para sus hijos. Y en este marco, hasta el momento, el Tribunal Supremo no ha encontrado en estos centros tacha alguna de inconstitucionalidad ${ }^{10}$.

\section{REFERENCIA HISTÓRICA Y ACTUALIDAD DE LA EDUCACIÓN SINGLE-SEX EN EE.UU.}

En los Estados Unidos existe una tradición arraigada de colegios single-sex privados, tanto de niños, como de niñas, distinguidos por su excelencia académica y fuerte personalidad. Las escuelas para niñas adquirieron especial fuerza a principios del siglo XIX como centros escolares de ideología feminista cuya pretensión principal era impulsar la educación de las mujeres en condiciones de igualdad con los hombres. Se trataba de centros pioneros, muy progresistas para su época, y claramente reivindicativos de una posición destacada para la mujer en un momento histórico en el que la cultura dominante les negaba el derecho a la igualdad ${ }^{11}$.

Los colegios e institutos privados, masculinos y femeninos, siempre han estado permitidos por el ordenamiento jurídico norteamericano y continúan actualmente con gran implantación entre el sector más acomodado de la población norteamericana, sin que se cuestione en absoluto su legitimidad.

No ha sucedido lo mismo, sin embargo, con los colegios públicos o aquellos centros que reciben algún tipo de financiación pública -Charter School; Performance School y Contract School_. Estos, durante los años setenta, fueron progresivamente transformándose en centros mixtos, especialmente desde que, en 1972, bajo la presidencia de Nixon, y debido a la fuerte presión ejercida por el entonces emergente feminismo igualitarista, impulsado por los movimientos

Según la National Association of State Boards of Education Policy Update (2010): «Los beneficios de la educación separada, tanto para los chicos como para las niñas incluyen: mayor nivel en la lectura y comprensión lectora; una mejora en el aprendizaje de lenguas extranjeras; una disminución de los estereotipos sexuales; más tiempo dedicado al estudio y deberes en el hogar; y unas aspiraciones más altas. Los efectos positivos son enormes tanto para los niños como para las niñas, y muy especialmente para aquellos estudiantes pertenecientes a minorías...».

10 Vid. por todos, MARTÍNEZ LÓPEZ-MUÑIZ, J.L. (2011), «El derecho a la educación en los Estados Unidos de América», Revista española de derecho constitucional, 93, págs. 65-106.

11 De esa época destacan, entre otros, los colegios femeninos de Baltimore's Western High (1844) y Philadelphia High School for Girls (1848). 
juveniles del 68, la Ley federal prohibió —en su Título IX — la discriminación por razón de sexo en los centros escolares sostenidos con fondos públicos.

A partir de los años ochenta, EEUU comenzó a sufrir una grave crisis educativa. En 1983, la Comisión Nacional para la Excelencia en Educación publicó un informe sobre la situación en el país denominado: «Una Nación en peligro». Este informe finalizaba con una cita de Paul Copperman que decía lo siguiente: «Cada generación de americanos ha sobrepasado a sus padres en educación, alfabetización y logros económicos. Pero por primera vez en la historia de nuestro país, las habilidades aprendidas en la escuela por una generación no serán sobrepasadas ni alcanzadas ni igualadas, ni siquiera se acercarán a las de los padres».

Muchas fueron las variables que se manejaron buscando una explicación para el considerable aumento del fracaso escolar, el absentismo y la violencia en los institutos: el nivel social; la pertenencia a minorías; la renta o el aumento de divorcios; fueron algunos de los datos tenidos en cuenta. Sin embargo, el factor sexual no se consideró determinante hasta los años 90, cuando, en relación con las niñas, la crisis educativa comenzó a hacerse patente. En estos años, la Asociación Americana de Mujeres Universitarias publicó el artículo: «Shortchanging Girls, Shortchanging America» ${ }^{12}$, en el que se describía cómo en las aulas mixtas la autoestima de las niñas caía bruscamente durante la pubertad, haciéndoles perder el incentivo hacia las carreras de matemáticas y ciencias; y cómo los profesores prestaban mayor atención a los muchachos, más movidos e indisciplinados, dejando a las niñas en un segundo plano ${ }^{13}$.

Ya en 1982, la profesora de filosofía y psicología de Harvard, Carol Gilligan, con enorme influencia en la sociedad del momento, en especial en sectores feministas, en su libro, In a different voice, llamó la atención sobre la existencia de diferencias cognitivas entre niños y niñas ${ }^{14}$. Según Gilligan, existen aspectos únicos a los que se enfrentan las adolescentes en su lucha por desarrollar un sentido de sí mismas y parece que la educación mixta desatiende estas necesidades específicas de las niñas. Los chicos dominan el espacio, los profesores centran su atención en ellos, más movidos e inquietos, y las chicas pierden la oportunidad de participar en clase. Las mujeres como grupo difieren de los hombres en su orientación básica hacia la vida; lo que resulta absolutamente legítimo y no debe ser menospreciado: «La adolescencia es un periodo muy importante en

12 AMERICAN ASSOCIATION OF UNIVERSITY WOMEN EDUCATIONAL FOUNDATION (1992), The AAUW Report: How schools shortchange girls.

13 BURTON, L. (1990), «Gender and mathematics: An international perspective», 87-118. UNESCO, (1995), The scientific education of girls. N.U.

${ }^{14}$ GILLIGAN, C. (1982), In a different voice. Psychological, theory and women's development. 
el desarrollo femenino, un momento en el que las chicas corren el peligro de anularse o desaparecer ${ }^{15}$.

Esta caída pronunciada en el nivel académico generalizado provocó que en distritos escolares de más de una docena de Estados - Texas, Colorado, Michigan y Georgia, entre otros - se comenzaran a separar a alumnos y alumnas en algunas clases para mejorar los resultados y la convivencia ${ }^{16}$. La mayoría de los cambios pretendían que las alumnas mejorasen en matemáticas y ciencias y que los chicos trabajasen con más orden y disciplina. Ciudades, como Nueva York y Chicago, en la década de los 90, abrieron centros femeninos de enseñanza secundaria con el fin de reducir la diferencia de resultados con los chicos en matemáticas, ciencias o tecnología ${ }^{17}$. Un ejemplo emblemático lo constituye la Young Women's Lidership Academy (YWLA), ubicada en East Harlem (106th Street; N.Y). Se trata de un colegio público sólo para niñas que, desde que comenzó su funcionamiento en 1996, consigue tasas de éxito del $100 \%$ frente a la media del $42 \%$. Aunque el $90 \%$ de las alumnas procede de familias sin estudios (el $70 \%$ viven bajo el umbral de la pobreza), su acceso a la Universidad se ha convertido en una realidad habitual entre ellas ${ }^{18}$.

En 1994, el Gobierno Federal aprobó la Gender Equity in Education Act, una norma que identificaba a las niñas como el principal grupo en desventaja en el ámbito educativo y cuyo objetivo primordial era favorecerlas en todos los sentidos, ignorando, sin embargo, las necesidades peculiares de los chicos, así como la grave crisis en la que los varones comenzaban a adentrarse en el ámbito escolar ${ }^{19}$.

Respecto a los muchachos, la preocupación es mucho más reciente y tiene su origen en los datos reflejados por estadísticas y estudios que los sitúan am-

15 GILLIGAN, C.(1990), Preface, «Teaching Shakespeare's sisters: notes from underground of female adolescence», Making Connections, 10. En la misma línea vid. ORENSTEIN'S, P. (1994), School Girls. Sadker and Sadker's, Failing and Fairness.

16 Newsweek, 24-VI-96.

17 Las matrículas en colegios privados femeninos se dispararon en la década de los 90, pasando de 2.000, entre 1995 a 1996, a 3.500 más, entre 1997 y 1998. Datos extraídos de National Ass'n of indep.schss. Backgrounder: single-sex independent schools (1999).

${ }_{18} \mathrm{Vid}$. al respecto. http://www.ywln.org/. Este centro escolar realiza además una labor de inmensa relevancia con las madres solteras adolescentes, a las que se les dan toda clase de facilidades para que no abandonen los estudios (guarderías; ayudas económicas; apoyo social y psicológico...).

19 Sobre los problemas específicos de los varones, Vid. KLEINFELD, J. (2009) The state of american boybood. COHEN, D.S. (2009), «No Boy Left Behind - Single-Sex Education and the Essentialist Myth of Masculinity», 84 IND. L.J.135, 138. TYRE, P, (2006), The Trouble with Boys, NEWSWEEK, Jan. 30.

http://www.newsweek.com/id/47522/page/1. RIGDON, R. (2008), «Dangerous Data: How Disputed Research Legalized Public Single-Sex Education», 37, STETSON L. REV. 527, 549. 
pliamente por detrás de las niñas en cuanto a resultados académicos y acceso a la universidad ${ }^{20}$. A principios de los 90, algunos distritos escolares, entre ellos Detroit y Nueva York, intentaron luchar contra los problemas de delincuencia y abandono escolar de los chicos por medio de la apertura de centros masculinos, algunos de los cuales fueron dotados con un programa de estudios especialmente enfocado hacia los varones afroamericanos ${ }^{21}$.

A inicios del nuevo siglo el fracaso escolar y el bajo rendimiento académico comenzaban a estar generalizados en las escuelas públicas con cifras verdaderamente alarmantes. Lo que provocó que republicanos y demócratas aunaran sus esfuerzos en la búsqueda de una solución adecuada por medio de la aprobación, en diciembre de 2001, de una nueva ley federal, sancionada por el Presidente Bush el 8 de enero de 2002: No Child Bebind Act ${ }^{22}$. En cuya virtud se concedió a

20 Según datos recientes del Departamento de Educación, los niños en secundaria están más de 10 puntos por debajo de las niñas en comprensión lectora y más de 24 puntos en escritura. A los doce años, los chicos que repiten algún curso duplican a las chicas. También son la mayoría de los que abandonan los estudios en secundaria. Se les diagnostica déficit de atención con hiperactividad hasta tres veces más que a las niñas y se les atribuyen hasta el doble de desórdenes de conducta. Los chicos se suicidan 3,5 veces más que las chicas. Tienen mayor tendencia a considerar que el colegio y los estudios carecen de sentido y no aportan nada. Muchos más niños protagonizan acoso escolar y episodios de violencia o consumo de drogas dentro del colegio. Nueve de cada 10 actos delictivos relacionados con alcohol o drogas son protagonizados por chicos. Estos datos se agravan aún más en relación con minorías. Así, por ejemplo, las estadísticas muestran que el $50 \%$ de los chicos negros en edad escolar tienen antecedentes delictivos. Sólo en el área de Washington, DC, los chicos suspenden tres veces más que las niñas en primaria; el doble de chicos se encuentra recibiendo algún tipo de educación especial; el $76 \%$ de los niños en primaria no saben a penas leer y el $84 \%$ de los niños también en primaria no dan los niveles mínimos exigidos.

Sobre la crisis académica de los varones, ver las estadísticas previstas en: The Nation's Report Card, the National Assessment of Educational Progress (NAEP), 2004, «Trends in Academic Progress, Three Decades of Student Performance in Reading and Mathematics», U.S. Department of Education, Institute of Education Sciences, NCES 2005-464. Ver también: KAFER, K, 2007, Position Paper No. 604, April, INDEPENDENT WOMEN' S FORUM: WOMEN FOR SCHOOL CHOICE, 2001, «Taking the Boy Crisis in Education Seriously: How School Choice Can Boost Achievement Among Boys and Girls. What about the boys?» Issues of masculinity in schools; edited by Wayne Martino and Bob Meyenn; Open University Press, Buckingham, Philadelphia. GLENN, S., 2003, The Boy Crisis in Education: What Can Be Done About It, Young Men's Initiative.

${ }^{21}$ Vid. http://eagleacademyfoundation.com/home.htm; The 2010 Schott 50 State Report on Public Education and Black Males; Schott Foundation for Public Education.

${ }^{22}$ No Child Left Behind (NCLB): is a government act instituted in 2001 which is a continuation of the President Johnson Elementary and Secondary Education Act. Its design is «to close the achievement gap with accountability, flexibility, and choice, so that no child is left behind» (US Department of Education, 2009). 
los padres y a los centros mayor flexibilidad para implementar experiencias novedosas («innovative assistance programs») que ayudasen de algún modo a mejorar la situación. Su pretensión principal era elevar el nivel en matemáticas y comprensión lectora hasta alcanzar los estándares federales impuestos para el año 2014.

La mayor autonomía de los centros públicos; la participación amplia de los padres en la gestión; la experimentación de modelos pedagógicos innovadores; la atención a las diferencias personales en el aprendizaje o los programas de financiación para estudiantes con escasos ingresos; fueron algunas de las novedades más destacables de esta Ley que concede enorme libertad a los Estados y Ayuntamientos en la gestión de sus centros escolares para la implantación de experiencias y programas innovadores (como las clases single-sex) y cuyo objetivo prioritario, según un portavoz de presidencia, es «ampliar las opciones de los padres» ${ }^{23}$.

En el año 2006, se llevó a cabo el desarrollo reglamentario de la No Child Behind Act, determinante para la implementación de experiencias single-sex en las escuelas públicas o que reciben algún tipo de financiación pública.

Ese mismo año, Doug Anglin, un joven de 17 años, en Milton, Massachusets, había presentado una queja ante el Departamento de Educación de los Estados Unidos, por entender que su Instituto — donde las niñas duplicaban a los muchachos en premio de estudios - violaba sus derechos civiles, discriminándole por el hecho de ser varón. Su caso no acabó residenciado ante los tribunales, pero sí obtuvo una enorme repercusión mediática, lo que provocó posteriormente el apoyo de congresistas y senadores, favoreciendo el cambio de la legislación ${ }^{24}$.

En la actualidad, son muchos los centros públicos que están desarrollando con éxito este tipo de programas single-sex ${ }^{25}$. Y la demanda de los padres sigue progresivamente en aumento ${ }^{26}$.

${ }^{23}$ En marzo de 2004, el Departamento de Educación concedió aun mayor flexibilidad y facilidades para implementar experiencias single sex (Nondiscrimination on the basis of sex in education programs or activities reveiving federal financial assistance, 69, fed. reg. 1, 276, 2004) Pero la verdad es que muchos centros escolares no se atrevieron a hacerlo debido a la presión de los grupos de defensa de los derechos civiles, especialmente de la ACLU.

${ }^{24}$ KLEINFELD, J. (2009), «The State of American Boyhood», Gender Issues.26, 113-120.

25 Cientos de centros escolares están experimentando con clases single sex. La mayoría de los colegios diferenciados sirven al interés de minorías desfavorecidas (alumnos calificados «en riesgo») con excelentes resultados. El 75\% de los colegios diferenciados han abierto desde 2005, un incremento del $300 \%$. La ciudad de NY alberga el 20.6\% de los colegios diferenciados de la Nación, con la mayor concentración de colegios públicos diferenciados en un área metropolitana en los EEUU. En el Estado de NY se encuentra el 25\% de los colegios públicos diferenciados de EEUU, más que en cualquier otro Estado.

26 Por ejemplo, en el curso 2010-2011, el colegio público Foley Intermediate, en Alabama, recibió un $87 \%$ de peticiones de los padres solicitando clases diferenciadas para sus hijos e hijas. 
No obstante, una de las mayores preocupaciones del Gobierno y la Administración sigue siendo la elevadísima concentración del fracaso escolar entre la población latina y afroamericana ${ }^{27}$. Para dar solución a esta problemática, la Administración pública está destinado millones de dólares a financiar programas experimentales y a abrir nuevas líneas de investigación sobre los beneficios de la educación diferenciada en relación con las minorías y áreas socio-económicamente deprimidas ${ }^{28}$.

En los últimos años, el crecimiento de los colegios e institutos públicos diferenciados en EEUU ha sido espectacular. En marzo de 2002, cuando se fundó la National Association Single Sex Public Asociation (NASSPE) ${ }^{29}$, solo una docena de centros públicos ofrecían educación diferenciada por sexo. Sin embargo, en 2009, tenían 1890 escuelas con algún tipo de educación diferenciada (sin contar las que separan para las clases de educación física o sexual, que son muchas más). Para el curso 2011-12 eran públicas al menos 506, y de entre éstas, unas 110 eran íntegramente escuelas single-sex (66 de chicas y 44 de chicos) $)^{30}$. Desde 2002, más de 400 escuelas públicas se han convertido total o parcialmente en single sex. En el sector privado, más del $5 \%$ son diferenciadas por sexo (3.719 colegios), la mayoría no pertenecientes a instituciones religiosas ${ }^{31}$. Sólo

La Directora de este centro ha percibido en estas clases menos problemas de disciplina y mejores resultados en comprensión lectora y matemáticas.

${ }^{27}$ En la actualidad, hay más jóvenes afroamericanos en las prisiones que en las universidades. SALOMONE, R. (2004), «Feminist voices in the debate over single-sex schooling: finding common ground», Michigan Journal of Gender and Law, vol. II, issue I, pág. 77.

${ }^{28}$ En este sentido, resulta aleccionador el supuesto de Thurgood Marshall Elementary School, en Seattle, donde, en 2001, tras el primer año de experiencia con clases single-sex, el porcentaje de varones que alcanzó los estándares académicos exigidos estatalmente aumentó del 10 al 35\% en matemáticas, y del 10 al $53 \%$ en lectura y escritura. Otro ejemplo exitoso lo encontramos en Septima Clark Public Charter School, en Washington, DC, que se ha convertido en la opción estratégica de aquellos padres que desean para sus hijos afroamericanos una educación capaz de garantizarles un fututo en igualdad de oportunidades con los muchachos de raza blanca o de nivel socioeconómico más elevado. Asimismo, en Baltimore, el colegio público masculino Bluford Drew Jemison Science Technology Engineering Math Academy, donde prácticamente el 100\% de los alumnos pertenecen a algún tipo de minoría, es actualmente uno de los únicos tres colegios de la ciudad que ha logrado alcanzar los estándares académicos exigidos legalmente.

29 www.singlesexschools.org/

${ }^{30}$ Puede verse el listado en http://www.singlesexschools.org/schools-schools.htm.

31 Según un análisis de 2008 sobre 107 países del mundo, resulta que hay unos 200.000 centros escolares públicos o estatales y 14.000 privados o no gubernamentales con educación diferenciada, lo que supone una cifra de más de 40 millones de chicos o chicas escolarizados bajo esa modalidad educativa. 
en Carolina del Sur ${ }^{32}$, por ejemplo, el 34\% de las escuelas públicas tienen implantado este modelo con excelentes resultados, como muestran los estudios y estadísticas $^{33}$.

Desde que llegó Barack Obama a la Presidencia del Gobierno de los Estados Unidos, la educación diferenciada ha recibido un entusiasta impulso. La Administración pública está destinado millones de dólares a financiar programas experimentales en este ámbito y a abrir nuevas líneas de investigación ${ }^{34}$. El Secretario de Educación, Arne Duncan, lleva años luchando por la implantación de este modelo educativo en las escuelas públicas, donde ha logrado la realización de experiencias absolutamente exitosas ${ }^{35}$.

Las nuevas escuelas diferenciadas reciben un apoyo variado, desde republicanos a demócratas, pasando por neofeministas e investigadores progresistas ${ }^{36}$.

32 Para la implantación de esta experiencia escolar más de 300 profesores recibieron formación sobre las peculiaridades de cada sexo en el aprendizaje, mediante cursos impartidos por la Office of Public School Choice del Departamento de Educación del Estado de Carolina del Sur, dirigida por David Chadwell.

33 See Nat'l Assoc. for Single Sex Public Educ. «Single-Sex Schools /Schools with Single-Sex Classrooms/What's the Difference?» http://www.singlesexschools.org/schools-schools.htm

34 En este sentido, merece la pena citar un proyecto de investigación específico del Departamento de Educación de Estados Unidos, dirigido por el sociólogo Cornelius Riordan, titulado: Escuelas públicas diferenciadas. Características y logros, cuyos resultados vienen a confirmar lo que la práctica ya está demostrando: que la atención a las diferencias sexuales en el aprendizaje mejora la convivencia en el aula y el rendimiento académico tanto de niños como de niñas; especialmente en relación con las minorías y población económicamente deprimida. RIORDAN, C. (1996), Public Education: Issues Involving Single-Gender Schools and Programs (Washington, D.C. General Accounting Office).

35 Por ejemplo, gracias a su impulso y apoyo explícito, en el 2002, en el Sur de Chicago, se creó el Urban Prep Charter Academy for Young Men, un instituto público exclusivo para chicos, de familias pobres en su mayoría, que está dando cuotas de éxito escolar absolutamente increíbles (prácticamente el 100\% han accedido a la universidad), teniendo en cuenta que lo habitual, según muestran las estadísticas, es que sólo se gradúe uno de cada 40 muchachos afroamericanos. Vid. al respecto: www.urbanprep.org. HORTON, A. (2010), Academy of Achievers: All Chicago Charter School's Seniors Get Into College, Jet Magazine, April. http://www.urbanprep.org/pdf/EbonyJetMag_Apr2010.pdf.

${ }^{36}$ Entre los demócratas destaca la actual Secretaria de Estado Hillary Clinton (alumna de uno de los 84 centros universitarios sólo para chicas de Estados Unidos, el Wesllesley College). Entre los republicanos defensores de este modelo podemos citar asimismo a la senadora Susan Collins [R-ME], Congressional Record, June 7, 2001, S5944). En este sentido, merece la pena destacar el artículo publicado recientemente en el Wall Street Journal por Ms. Hutchison, Senadora republicana, junto a Ms. Mikulski, Senadora demócrata, sobre el derecho a elegir la educación diferenciada por sexo. COLLINS \& HUTCHISON, (2012), "A right to choose single-sex education», en Wall Street Journal | Oct 17. 
Sin embargo, también cuentan con detractores. Algunos grupos feministas, como la Feminist Majority Foundation y la National Organization for Women, creen que estos centros debilitan los resultados políticos a favor de la igualdad de la mujer obtenidos a lo largo de los últimos años del siglo $\mathrm{XX}^{37}$.También los defensores a ultranza de la escuela pública, temen que la financiación de estos centros suponga un detrimento para la financiación de los centros mixtos estrictamente públicos.

Pero la oposición más radicalizada hacia este tipo de escuelas proviene de la Asociación Americana de Defensa de los Derechos Civiles (American Civil Liberties Union; ACLU) ${ }^{38}$. Algunos de sus miembros consideran que estos centros violan las prohibiciones constitucionales y federales contra la discriminación sexual en la enseñanza, en concreto el Título IX de la Ley federal que prohíbe la discriminación por razón de sexo ${ }^{39}$. En la última década, la ACLU ha puesto todo su empeño en eliminar cualquier experiencia single-sex en los colegios públicos o que reciben algún tipo de financiación pública. Desde Detroit y Milwaukee a Philadephia, Nueva York o Chicago, los miembros de esta organización han interpuesto distintos tipos de acciones legales en el intento de frenar una tendencia que parece imparable.

\section{CONSTITUCIONALIDAD Y LEGALIDAD DE LA EDUCACIÓN SINGLE SEX}

\section{Los colegios single-sex ¿discriminan por razón de sexo? \\ La enmienda XIV a la Constitución de los EEUU. «Equal protection clause»}

La primera cuestión a plantear jurídicamente sobre la educación diferenciada sería la de su posible carácter discriminatorio: si al separar a niños y niñas en

${ }^{37}$ NATIONAL ORGANIZATION FOR WOMEN, (2007), Below the Belt: Looking at Education through Father Knows Best-Colored Glasses, Sept. 19, Feminist Majority Foundation - Education Equality, http://feminist.org/education/SexSegregation.asp.

38 No obstante, algunos miembros de la ACLU se han manifestado expresamente a favor de la educación single-sex. En esta línea, vid. ESTRICH, S. (1998), (former National Campaign Manager for Dukakis for President; former National Board Member of the ACLU; former aide to Sen. Ted Kennedy), «Ideologues Decry Single-Sex Education, But Girls Benefit,» Denver Post, May 22, B-11: «Si los distritos escolares quieren ofrecer programas single-sex, y los padres lo demandan, y los niños y niñas quieren ir a clases diferenciadas...entonces, debería existir el derecho a poder acceder a este tipo de centros...». Sin olvidar también a la magistrada del TS, R.Ginsburg, ardiente defensora de la educación diferenciada y que fue fundadora de esta organización.

39 Vid. 20 U.S.C. $§ 1681$ (2000). 
aulas diferentes se está discriminando a alguno de los sexos, es decir, perjudicando a uno de ellos o menoscabando sus derechos ${ }^{40}$.

En general, como nos recuerda Martínez López-Muñiz, no toda diferencia de trato a las personas da lugar a discriminación ${ }^{41}$. Es doctrina clara y constante establecida por los Tribunales Constitucionales y por el Tribunal Europeo de Derechos Humanos que una distinción será discriminatoria si carece de «justificación objetiva y razonable», si no persigue un «objetivo legítimo» o «si no existe relación razonable de proporcionalidad entre los medios empleados y el objetivo perseguido» ${ }^{42}$.

En el ámbito internacional, el art. 2 de la Convención de 1960 de la UNESCO sobre discriminación en la esfera de la educación, despeja cualquier posible duda al respecto, al disponer con claridad que no son discriminatorias: "La creación o mantenimiento de sistemas o establecimientos de enseñanza separados para los alumnos de sexo masculino y para los de sexo femenino, siempre que estos sistemas o establecimientos ofrezcan facilidades equivalentes de acceso a la enseñanza, dispongan de un

${ }^{40}$ En España, el Tribunal Supremo, en Sentencia de 2006, afirmó que: «No se puede asociar la enseñanza separada (por sexos) con la discriminación por razón de sexo» (Sentencia de la sección $7 .{ }^{2}$ de la sala $3^{\text {a }}$, de 26 de junio de 2006, fto. 8). Criterio reiterado por sentencias posteriores.

41 MARTÍNEZ LÓPEZ-MUÑIZ, J.L. (2012), «Escolarización homogénea por razón del sexo y derecho fundamental a la educación en libertad», en la REDA, núm. 154, págs. 78-80.

${ }^{42}$ Nuestro Tribunal Constitucional, en la mayor parte de sus sentencias referidas al artículo 9.2, ha interpretado dicho precepto como un correctivo del principio de igualdad formal del artículo 14, haciendo hincapié en la necesidad de que el legislador no trate a todos los individuos de la misma manera sino que sea capaz de tratar de forma diferente aquellas situaciones que son distintas en la vida real. Así, ha afirmado en varias sentencias que «lo proclamado en el artículo 9.2 puede exigir un mínimo de desigualdad formal para progresar hacia la consecución de la igualdad sustancial» Vid. al respecto, fundamentalmente, las sentencias 114/1983, de 6 de diciembre; 98/1985, de 29 de julio, y 19/1988, de 16 de febrero. En este sentido conviene recordar lo dispuesto en la STC 65/1983, de 21 de julio: «Este principio (el de igualdad) vincula a todos los poderes públicos incluido el legislativo (...), pero no prohíbe que el legislador contemple la necesidad o conveniencia de diferenciar situaciones distintas y darles un tratamiento diverso, siempre que no vulnere otros preceptos constitucionales y que no vaya contra la esencia del principio de igualdad (...)». Y, en la misma línea, la STC 25/1989, de 3 de febrero: «Como este Tribunal viene declarando reiteradamente (...) el principio de igualdad (del artículo 14) no prohíbe toda diferencia de trato; dicho principio sólo puede entenderse vulnerado cuando la desigualdad denunciada está desprovista de una justificación objetiva y razonable, y la existencia de esta justificación ha de apreciarse en relación con la finalidad y efectos de la medida considerada, debiendo darse una razonable proporcionalidad entre medios y fines». Vid. por todos, E. CARMONA CUENCA, (1994), «El principio de igualdad material en la jurisprudencia del tribunal constitucional», Revista de Estudios Políticos (Nueva Época), núm. 84. Abril-Junio. 
personal docente igualmente cualificado, así como de locales escolares y un equipo de igual calidad y permitan seguir los mismos programas de estudio o programas equivalentes» ${ }^{43}$.

Estados Unidos no ha ratificado este Tratado, sin embargo, como veremos más adelante, su jurisprudencia, sostiene un criterio muy similar al previsto en el art. 2 de la Convención citada.

Entender de forma generalizada y abstracta que la educación diferenciada es discriminatoria constituye una simplificación errónea de la realidad provocada por la confusión entre igualdad y uniformidad, más aún, entre igualdad e igualitarismo. La separación por sexo en las escuelas no es per se discriminatoria, en tanto en cuanto no se demuestre fehacientemente y con referencia a casos concretos que uno de los sexos resulta perjudicado o sus derechos menoscabados.

La enmienda XIV de la Constitución norteamericana consagra la igualdad ante la Ley de todos los ciudadanos, sea cual sea su sexo, raza o clase: «Ningún estado... negará a persona alguna dentro de su jurisdicción la protección igual de las leyes» («equal-protection scrutiny») ${ }^{44}$.

El Tribunal Supremo norteamericano, hasta ahora, ha seguido distintos métodos de análisis de la constitucionalidad del trato diferenciado según se trate de diferenciación por raza, clase o sexo: 1) Con un escrutinio estricto, cuando se trata de discriminación por raza o nacionalidad. Solo se permite el trato desigual en estas ocasiones cuando el gobierno pueda demostrar que la segregación racial sirve a un interés prioritario del gobierno y que la separación está íntima y estrechamente relacionada con el mismo. 2) Con un escrutinio más flexible, cuando se juzga la constitucionalidad de la separación por sexo («separate but equal»).

a) Separación por raza en las escuelas públicas

A día de hoy el Tribunal Supremo ha encontrado justificación para flexibilizar el rígido escrutinio estricto relativo a la raza únicamente en tres ocasiones: 1) en un caso de la segunda guerra mundial que justificaba el internamiento de los japoneses americanos; 2) en un caso de 1980, justificando una cuota del $50 \%$ de empleados negros en el Departamento del Sheriff de Alabama; y 3) en 2003, cuando el Tribunal Supremo admitió una "affirmative action» interpuesta por la Universidad de Michigan sobre la política de admisión de alumnos.

Salvo tales excepciones, el Tribunal Supremo considera que los alumnos resultan a priori perjudicados cuando se les separa por motivos raciales porque tal

43 Tratado ratificado por España el 20 de agosto de 1969 y plenamente vigente.

44 «No state shall... deny to any person within its jurisdiction the equal protection of the laws». 
separación "provoca sentimientos de inferioridad... que pueden afectar a los estudiantes emocional y mentalmente de forma inadmisible» ${ }^{45}$. Y esto aunque las infraestructuras y medios proporcionados sean los mismos ${ }^{46}$.

En esta línea, el TS ha considerado siempre ilegal e inconstitucional cualquier separación por motivos de raza en el ámbito escolar. En 1860, cuando comenzó la educación pública en EEUU, los colegios aplicaban la separación por raza en las escuelas de forma generalizada. Más tarde, en 1954, el Tribunal Supremo revisó la segregación racial en el caso Brown v. Board of Education of Topeka. Las circunstancias habían cambiado mucho después de la segunda guerra mundial cuando surgió una fuerte presión internacional para dar fin a la discriminación racial. También dentro de los EEUU se produjeron considerables movimientos de concienciación para reconciliar la política nacional con los principios básicos del país en materia de igualdad (Wolters, 2008). En los años 50 era evidente que la separación entre blancos y negros en las escuelas resultaba insostenible con argumentos de igualdad. Entonces el Tribunal Supremo aplicó la enmienda XIV de la Constitución al caso Brown argumentando que la doctrina «separados pero iguales» («separate but equal») no resultaba aplicable en el ámbito de la educación pública ${ }^{47}$. Desde entonces y hasta la actualidad, la segregación racial en las escuelas e institutos públicos de los Estados Unidos está prohibida.

Esta decisión fue más ideológica que práctica en muchos sentidos. Mientras se prohibía expresamente la segregación racial en las escuelas, en muchos centros escolares los alumnos tendían a seguir separados y agruparse espontáneamente según el color de su piel. En estos casos, en los que la integración fracasaba de hecho, el Estado no podía obligar o forzar a la integración racial de los estudiantes (Wolters, 2008).

En la actualidad, aunque en teoría la segregación racial en las escuelas está prohibida, permanece de facto, dada la existencia de barrios enteros ocupados por minorías y, en consecuencia, los centros públicos ubicados en esas zonas están copados por latinos o alumnos de color. Sin embargo, no es una separación

45 "Generates a feeling of inferiority... that may affect (students') bearts and minds in a way unlikely to ever be undone.» (Brown v. Bd. of Educ. of Topeka, 347 U.S. 483, 494 (1954).

46 Brown v. Bd. of Educ. of Topeka, 347 U.S. 493 (1954).

47 En 1896, el Tribunal Supremo cuestionó la segregación racial en el caso Plessey v. Ferguson; que implicaba sustituir la sanción de arresto a una persona de color por un trabajo como conductor de un tren reservado solo para pasajeros blancos. El Tribunal Supremo mantuvo el arresto considerando que la segregación racial era permisible si las infraestructuras prestadas por los negros eran iguales a las reservadas a los blancos (Ware, 2008). Este fue el principio de la doctrina conocida como «separados pero iguales» («separate but equal»). 
impuesta, sino debida a las circunstancias que rodean la configuración de las comunidades raciales en Estados Unidos.

b) Separación por sexo en las escuelas públicas

En relación con la separación por sexo en las aulas, han sido únicamente dos los casos resueltos por el Tribunal Supremo hasta ahora, aunque no referidos a colegios o institutos públicos estrictamente, sino a centros de formación militar o enseñanza profesional sostenidos con fondos públicos ${ }^{48}$.

En el primero de ellos, en 1982, Mississippi University for Women v. Hogan, el TS consideró inconstitucional esta escuela universitaria de enfermería, fundada en 1884 y reservada a mujeres, al no encontrar un fundamento razonable que justificase la exclusión de hombres de la misma; afirmando que tal restricción al acceso masculino se basaba en estereotipos arcaicos y colaboraba a "perpetuar el estereotipo de considerar la enfermería como un trabajo exclusivamente femenino» ${ }^{49}$.

En este caso, sin embargo, el TS dejó abierta la posibilidad de centros de enseñanza single-sex siempre y cuando no sirvieran para promover roles obsoletos $\mathrm{y}$ anticuados sobre las diferentes habilidades de hombres y mujeres ${ }^{50}$.

Catorce años más tarde, en el caso United States v. Virginia (1996), el TS nuevamente consideró inconstitucional la separación por sexo en un centro académico militar de Virginia en el que sólo se admitían hombres. "Las generalizaciones sobre cómo son las mujeres o lo que se estima apropiado para la mayoría de las mujeres, no justifica en absoluto la posibilidad de negar la oportunidad a aquellas cuyos talentos $y$ capacidades las sitúen fuera de la generalidad, perpetuando así los estereotipos...».

En este caso, el TS concluyó que la Academia Militar de Virginia violaba la constitución («equal protection clause»), pero al mismo tiempo el alto tribunal ofreció tres soluciones para remediar la inconstitucionalidad: 1) admitir mujeres; 2) ofrecer a las mujeres formación equiparable en otro centro similar; y 3) transformarse en un centro estrictamente privado renunciando a todas las ayu-

48 Como señala acertadamente Martínez López-Muñiz, con respecto a centros públicos de enseñanza general, hasta ahora, solo una vez se planteó ante el TS un supuesto en 1976 que, sin embargo, no llegó a progresar. MARTÍNEZ LÓPEZ-MUÑIZ, J.L. (2012), «Escolarización homogénea por razón del sexo y derecho fundamental a la educación en libertad», en REDA, n. 154, pág. 91. Vid. sobre este caso concreto, A. NOVICK y D. GRIFNTHS. (1978), «Sex-Segregated Public Schools: Vorchheimer v. School District of Philadelphia and the Judicial Definition of an Equal Education for Women», 4 Women's Rights L. Rep. 79.

49 Mississippi University for Women v. Hogan, 458 U.S. 718-31 (1982).

50 SALOMONE, R. (2000), «Rich kids, poor kids and the single sex education debate», Akran Law Review. 
das públicas (los centros privados pueden aplicar la separación por sexos sin que se cuestione su constitucionalidad).

Este supuesto se planteaba en un momento histórico-social muy diferente al del caso Mississippi University for Women v. Hogan. En los años 90, la educación diferenciada comenzaba a implantarse seriamente en centros escolares públicos con un amplio respaldo social y un apasionado apoyo de los dos principales partidos políticos, así como de la presidencia del Gobierno federal, que lejos de ver en la educación single-sex una violación de la clausula de igualdad ante la Ley, la considera precisamente el remedio o la garantía para el acceso a la educación en condiciones de igualdad de ciertas minorías desfavorecidas.

Paradójicamente, el mismo año en que se dictó la sentencia, 1996, con un amplísimo respaldo social y amparados por una fuerte campaña de apoyo por parte de periodistas y medios de difusión, se inauguró la escuela pública femenina Young Women's Lidership Academy (YWLA) en Harlem; una oportunidad para niñas pobres de color de alcanzar una auténtica igualdad de oportunidades en el ámbito educativo ${ }^{51}$.

En este caso, la magistrada Ruth Bader Ginsburg — primera mujer que accedió al Tribunal Supremo, de talante liberal y conocida por su lucha contra la discriminación por sexos-, sabiendo la trascendencia que el supuesto podría tener para estas nuevas instituciones single sex, así como para otras más tradicionales (como la prestigiosa universidad de mujeres Wellesley college, en la que se formó Hillary Clinton) realizó una serie de matizaciones. Ginsburg, expresando la opinión de la mayoría del Tribunal, reconoció que, a diferencia de la raza, entre los sexos existen «diferencias inherentes» («...that are cause of celebration...»), «los sexos no son fungibles» ${ }^{52}$. Pero al mismo tiempo señaló que esas diferencias entre los sexos «...nunca deben ser utilizadas para crear o perpetuar

51 A partir de esa experiencia se creó una Fundación encargada de la promoción de otros centros docentes similares que tiene ya una red de centros para 1.652 chicas en entornos económicamente desfavorecidos de entre 12 y 18 años en New York, Philadelphia y Chicago. En 2007-2008 la procedencia de esas alumnas era: $51 \%$ afroamericana, 35\% latinas, $9 \%$ asiáticas y $5 \%$ de otras procedencias. En la misma línea, para chicos de entornos deprimidos merece la pena destacar las experiencias de Urban Prep en Chicago, y Eagle Academy en New York.

52 Virginia, 518, US, at 533. Parte de nuestra doctrina constitucionalista ignora o desprecia esta dualidad considerando que el derecho al desarrollo de la personalidad y la educación solo puede concebirse a partir de la negación absoluta de la existencia de diferencias entre los sexos y, en consecuencia, cuestionando la constitucionalidad de aquellos modelos educativos que atienden de forma específica a las peculiaridades que niños y niñas presentan en los procesos de aprendizaje. Vid. en este sentido, ALÁEZ CORRAL, B, (2009), «El ideario educativo constitucional como fundamento de la exclusión de la educación diferenciada por sexo de la financiación pública», Revista Española de Derecho Constitucional, n.86, mayo-agosto, págs. 31-64. 
estereotipos... o como en el pasado, la inferioridad de las mujeres», y afirmó que la separación por sexos puede estar justificada en ocasiones, como sucede con algunas escuelas públicas de niñas y jóvenes, siempre y cuando esté íntimamente unida ( «substantially related») a un importante interés del Gobierno («important governmental interest») que sirva de justificación razonable a tal separación («exceedingly presuasive justification») y siempre que se ofrezca al otro sexo un programa educativo substancialmente igual («substantially equall»), sin necesidad de que sea exactamente idéntico.

En definitiva, las decisiones deben ser adoptadas caso por caso, teniendo siempre presente que las diferenciaciones por sexo son válidas dentro de ciertas circunstancias y, en consecuencia, el modelo single-sex en las escuelas públicas o que reciben fondos públicos, puede ser plenamente legal, siempre que sirva, en palabras de Ginsburg, para: «disipar, en lugar de perpetuar, los tradicionales estereotipos de sexo... las diferencias existen, pero no pueden nunca ser utilizadas para crear obstáculos artificiales que dificulten la igualdad de oportunidades. . Las diferenciaciones entre los sexos son admisibles en la medida en que permitan el desarrollo de las capacidades y talentos de los individuos de nuestra Nación... "s3.

Y trayendo a colación la doctrina prevista en el caso Sweatt v. Painter (1950), el TS recordó que la igualdad debe medirse en función de elementos tangibles e intangibles, incluyendo las oportunidades curriculares y extracurriculares, la formación del profesorado, los fondos que reciben, el prestigio, los recursos bibliográficos y el apoyo dado al alumnado ${ }^{54}$.

En el supuesto de la Academia Militar de Virginia, el problema no era que se reconocieran diferencias entre hombres y mujeres (que, como afirma Ginsburg, existen de hecho y son innegables) sino que se identificaban a priori las diferencias con desventajas (en este caso, incapacidad de la generalidad de las mujeres para superar el duro régimen aplicado en la academia masculina) ${ }^{55}$. La Academia alegaba que admitir a mujeres les supondría tener que rebajar el rigor y la exigencia para adaptarse a las características propias de la generalidad del sexo femenino, en detrimento de la dureza que caracterizaba su exitoso programa.

A diferencia de la separación por raza, el TS nunca ha considerado la separación por sexo en las escuelas públicas inconstitucional per se, siempre y cuando se ofrezca una opción de similares características al otro sexo (A.N.A. et al. v. Breckinridge County Board of Education (2011). Es decir, si se trata de un centro

53 Virginia, 518, US, at 533.

54 Virginia, 518, US at 551-53.

55 SUNSTEIN, C. (1999), One case at a time: judicial minimalism on the Supreme Court, Harvard University Press, pág. 165. 
de niñas, los chicos deben poder ser igualmente atendidos en un centro escolar de chicos o mixto en las cercanías (United States v. Virginia, 518 U.S. 515, 533 n. 7 (1996). En tales circunstancias, el poder de los estados para crear clases single-sex resulta perfectamente admisible ( «We do not question Virginia's prerogative evenhandedly to support diverse educational opportunities such as single sex schools» ${ }^{56}$.

El problema, tanto en el caso de Mississippi como en el Virginia, era precisamente la inexistencia de un centro público equivalente para el otro sexo ( "Mississippi maintains no other single-sex public university or college. Thus, we are not faced with the question of whether States can provide "separate but equal" undergraduate institutions for male and females. » $)^{57}$.

En conclusión, si el centro diferenciado ayuda a disipar los estereotipos y además ofrece una opción alternativa equivalente al otro sexo (sin necesidad de que tal experiencia sea idéntica ${ }^{58}$ ); la claúsula de igual protección de la enmienda XIV («Equal Protection Clause») resulta absolutamente respetada y tal separación será por lo tanto plenamente constitucional ( Gender Separate can be Equal» $)^{59}$.

En palabras de Martínez López-Muñiz, la agrupación escolar por razón de sexo puede ser admitida si la autoridad pública satisface la carga de justificar su necesidad y su razonable finalidad, sin excluir a las personas de un sexo u otro de poder cursar estudios de determinado tipo y con medios de similar calidad ${ }^{60}$.

La justificación razonable exigida por la jurisprudencia para justificar un trato diferenciado en estos casos se encuentra en argumentos científicos (sobre los diferentes ritmos de maduración cognitiva entre los sexos) ${ }^{61}$, pedagógicos

56 Miss. Univ. for Women v. Hogan, 458 U.S. 718, 720 n. 1 (1982).

57 Vid. en la misma línea, Vorchheimer v. Sch. Dist. of Philadelphia, 532 F.2d 880, 888 (3d Cir. 1976), aff d by an equally divided Court, 430 U.S. 703 (1977).

58 A.N.A. et al. v. Breckinridge County Board of Education (2011).

59 «While there were differences among teachers, during the periods I observed there were no differences in the ways the single-sex and coed classes were conducted. The teachers used the same classroom set-up, the same text books, the same instructional strategies, and the same behavior management techniques for their coed and singlesex clases». Campbell (plaintiffs' expert) Report, DN 234-17 at 4.

"Those teachers who teach both a co-ed class and a single sex class: offer the same curriculum to both classes; are using the same pacing (when and how long to teach a unit) for both types of classes; interact with their classes in the same demeanor; use the same instructional strategies for both; use the same formative (during the unit) and summative (the end of the unit) assessments. I saw no evidence in either type of single-sex classrooms that any stereotypical strategies are used for either girls or boys». Ronay (defendants' expert) Report, DN 219-15 at 16.

${ }^{60}$ J.L. MARTÍNEZ LÓPEZ-MUÑIZ (2012), «Escolarización homogénea por razón del sexo y derecho fundamental a la educación en libertad», en REDA, n. 154, pág. 91.

${ }^{61}$ Sobre los diferentes ritmos de maduración de niños y niñas y sus distintas estrategias cognitivas, vid. al respecto: CALVO CHARRO, M., (2009), Guia para una educación diferencia- 
(acerca de las diferentes formas de aprendizaje y comportamiento de los sexos) ${ }^{62}$ y prácticos (con un ambiente con menos distracciones y más relajado y homogéneo donde la docencia resulta más sencilla); así como en los resultados experimentados con mejoras patentes, no solo en disciplina y rendimiento académico (demostradas en estudios y estadísticas) $^{63}$, sino también en configuración de la

da, ed. Toromítico. GURIAN, M. (2001), Boys and girls learn differently! Ed. Jossey-Bass, San Francisco, USA. SAX, L, (2006), «Por qué el género importa: lo que los padres y profesores deberían saber acerca de la ciencia emergente de la diferencia de sexos», en VIDAL, E. (coord.) Diferentes, iguales, ¿juntos?: educación diferenciada, Ariel. Una explicación científica de tales diferencias podemos encontrarla en: BARON-COHEN, S., (2005), La gran diferencia, ed. Amat. BLAKEMORE, S.J. y FRITH, U. (2009), Cómo aprende el cerebro, ed. Ariel, Barcelona. BRIZENDINE, L. (2007), El cerebro femenino, ed.: RBA. VVAA. (2008), Hombres y mujeres. Cerebro y Educación, ed. Almuzara. DIAMOND, M. (1997), «Sex Reassignment and Birth: a long term review and clinical implications», Archives of Pediatrics and Adolescent medicine, n. 151, march. EMMONS MACCOBY, E. y JACKLIN, C. (1974), The psychology of sex differences, vol. 1, Palo Alto, California, Standford University Press. FISHER, H, (2001), El primer sexo, ed. Punto de lectura. LIJIMA, M., ARIKASA, O., MINAMOTO, F. y ARAI, Y. (2001), «Sex differences in children's free drawings», Hormones and behavior, 40, 99-104. KIMURA, D. (2004), Sexo y capacidades mentales, Ariel, Barcelona.

${ }^{62}$ Vid. al respecto, CALVO CHARRO, M. (2009), Guía para una educación diferenciada, ed: Toromítico. CALVO CHARRO, M. (2011), Educando para la igualdad, ed. EUNSA. Merece la pena atender a la bibliografía especializada al respecto: GURIAN, M., «Learning and Gender»; American School Board Journal; oct. 2006. GURIAN, M., STEVENS, K. y KING, K. (2008), Strategies for teaching boys and girls — elementary level. Ed. Jossey-Bass, San Francisco, USA. GURIAN, M., STEVENS, K. and KING, K. (2008), Strategies for teaching boys and girls - secondary level. Ed. Jossey-Bass, San Francisco, USA. U.S. DEPARTMENT OF EDUCATION, 2006; Nondiscrimination on the basis of sex in education programs or activities receiving federal financial assitance, Final rule Federal Register; October 25. U.S. DEPARTMENT OF EDUCATION, (2005), Single sex versus coeducational schooling: a systematic review; U.S. DEPARTMENT OF EDUCATION (Office of planning, evaluation and policy development) (2006). «Strategy 1: Educate Teachers on Gender Differences in Development and Learning, Five powerful strategies for connecting boys to schools», Paper for White House Conference on Helping America's Youth, Indianapolis, Indiana; June 6.

63 Esta mejora en el rendimiento afecta tanto a las niñas como a los niños. En relación con aquellas existen estudios que demuestran que las notas de chicas en clases diferenciadas llegan a ser hasta 1/3 más elevadas que las de chicas similares en colegios y aulas mixtos (estudio realizado por la National Foundation for Educational Research; 2002). En U.K. 81 de las 100 escuelas con mejores resultados son single-sex, y son tanto escuelas estatales -25 de las 29 incluidas en esas 100 son single sex - como independientes o privadas, y entre las 10 mejores sólo una es mixta. El Órgano Consultivo Oficial del Reino Unido (OFSED - Office for Standard in Education) ha recomendado la separación escolar por sexos para evitar las grandes diferencias educativas entre chicos y chicas que se vienen observando (EASSE, dossier La educación diferenciada en el mundo (una aportación a la cohesión social, la convivencia, la igualdad entre sexos y la excelencia académica en países avanzados, diciembre 2008, pág. 3 y 4). Sobre los beneficios vid. los estudios y estadísticas 
personalidad (mayor capacidad de liderazgo, más autoestima, mayores expectativas profesionales, más respeto hacia el sexo opuesto, rechazo de estereotipos... $)^{64}$.

\section{Legalidad de la educación single-sex. El Título IX y la No child Bebind Act ${ }^{65}$}

El Título IX de la legislación en materia educativa constituye probablemente la norma con mayor impacto en el sistema educativo federal norteamericano hasta la actualidad. Aprobada por la administración Nixon en 1972, esta norma prohibió cualquier discriminación por razón de raza o sexo en centros educativos que recibieran financiación pública (por lo tanto no afectaba a los centros estrictamente privados) $)^{66}$.

Durante años, el Departamento de Educación, en concreto la Oficina de Derechos Civiles (Department of Education's Office of Civil Rights; OCR) se encargó de su aplicación, prohibiendo la educación diferenciada por sexo en los centros subvencionados, con ciertas excepciones, como los Boys-Scouts (exentos del pago de impuestos) y para determinadas clases, como las de deporte y educación sexual. El motivo de tal prohibición era principalmente que en la década de los 70 la educación era todavía curricularmente diferente para niños y para

reflejados entre otras, en: http://www.singlesexschools.org/home.php; http://www.gsa.uk.com; http://www.theibsc.org/

${ }^{64}$ LEE, V.E.; MARKS, H. y BYRD, T. (1994), «Sexism in single-sex and coeducational secondary school classrooms». Sociology of Education. SALOMONE, R. (2003), Same, different, equal: rethinking single-sex schooling, New Haven \& London: Yale University Press. Ver datos y estudios derivados de las siguientes organizaciones: National Association for Single Sex Public Education [NASSPE - Estados Unidos] http://www.singlesexschools.org/home.php Girls' Schools Association [GSA - Reino Unido] http://www.gsa.uk.com. National Coalition of Girls' Schools [NCGS - Estados Unidos] http://www.ncgs.org/. The Alliance of Girls' Schools Australasia [AGSA - Australia] http://www.agsa.org.au/. International Boys' Schools Coalition [IBSC - Estados Unidos] http://www.theibsc.org/. European Association Single-Sex education [EASSE - Europa] http://www.easse.org/

65 Sobre la legalidad de la educación diferenciada en España, vid. MARTínEZ LÓPEZ-MUÑIZ, J.L. (2005), «Siete tesis sobre la legalidad de una educación escolar especializada por razón del sexo», en Barrio, J. M. (Dir.), Educación diferenciada, una opción razonable, Eunsa. En la misma línea, MARTÍNEZ LÓPEZ-MUÑIZ, J.L. (2012), «Escolarización homogénea por razón del sexo y derecho fundamental a la educación en libertad», en REDA, n. 154. En contra de estas posturas, ver ALÁEZ CORRAL, B. (2009), «El ideario educativo constitucional como fundamento de la exclusión de la educación diferenciada por sexo de la financiación pública», Revista Española de Derecho Constitucional, n. 86, mayo-agosto, 31-64.

66 Title IX of 1972 Ed Amendments states: «No person in the United States, on the basis of sex, can be excluded from participation in, be denied the benefits of, or be subjected to discrimination under any education program or activity receiving Federal financial assistance.» 
niñas y no garantizaba objetivamente la igualdad de oportunidades, sino que, por el contrario, preparaba a las niñas para permanecer en el ámbito privado, mientras dotaba a los muchachos de las habilidades precisas para desenvolverse en el mundo profesional y público; trato a todas luces discriminatorio para el sexo femenino.

No obstante, la doctrina de los Tribunales federales consideró que los colegios diferenciados por sexo no violaban las previsiones del Título IX siempre que esas diferencias curriculares desaparecieran y existiera una oferta equivalente para el otro sexo. Así, en el caso Williams v. McNair, el Tribunal apoyó el centro femenino Winthrop en Carolina del Sur, dada la existencia de otro equivalente para muchachos. En el caso Vorchbeimerv. School District of Philadelphia ${ }^{67}$, la Corte tercera aprobó la existencia de institutos separados para chicos y para chicas ya que ambos ofrecían los mismos estándares educativos. En Kirsein v Rector $\mathcal{E}$ Visitors, un Tribunal de distrito federal decidió que la Universidad de Virginia debía aceptar mujeres, no porque la educación single sex fuera inferior en calidad o inconstitucional, sino simplemente porque en ese Estado las mujeres no tenían una oferta similar ${ }^{68}$.

Bajo la presidencia de G.Bush, se consideró que, una vez alcanzada la igualdad formal en curriculums, metas, objetivos y exigencia académica entre niños y niñas en el sistema educativo norteamericano, estaban listos para experimentar con nuevos modelos pedagógicos con el objetivo prioritario de garantizar una igualdad de oportunidades real, pudiendo ser la educación diferenciada por sexo una forma realista de lograrlo, al atender con especial intensidad a las necesidades y peculiaridades propias de cada alumno y alumna ${ }^{69}$. Como afirmaba, la entonces Senadora Hillary Clinton: "No debería haber ningún obstáculo para of recer clases single-sex en los colegios públicos de EEUU... Debemos tener en cuenta los logros de estos colegios a lo largo y ancho de nuestro país. Sabemos que este modelo está favoreciendo e impulsando a los estudiantes y también a los padres. Por ello debería haber más centros escolares de este tipo.... ${ }^{70}$.

En palabras de la Senadora demócrata Barbara Mikulski: «Las últimas investigaciones cientificas afirman reiterativamente que los niños y las niñas tienen diferentes

${ }^{67}$ Asunto Susan Lynn Vorchheimer v. School District of Philadelphia [430 U.S. 703 (1977)].

${ }^{68}$ En la misma línea: Doe v. Vermilion Parish Sch. Bd.

Vid. al respecto LAND, J. L. (1977), «Not dead yet: the future of single-sex education alter United States v. Virginia», Stetson Law Review, vol. XXVII, págs. 297 y ss.

69 Sobre los beneficios de la reforma del Título IX, vid. KISELEWICH, R. A. (2008), «In Defense of the 2006 Title IX Regulations for Single-Sex Public Education: How Separate Can Be Equal», 49 B.C. L. REV. 217, 229.

${ }^{70}$ Congressional Record, June 7, 2001, S5943. 
formas de aprender y esta diferencia debe ser respetada. Sus detractores consideran que estos programas generan dañinos estereotipos de género, cuando la realidad es que el objetivo prioritario de las clases single-sex es precisamente acabar con tales estereotipos» ${ }^{71}$.

En el 2001, el Título IX fue objeto de revisión por medio de la aprobación de la No Child Left Bebind Act $(N C L B)^{72}$, que adaptó la norma a la doctrina del Tribunal Supremo expuesta. Ese mismo año, la senadora republicana Kay Bailey Hutchison de Texas, y la senadora demócrata Hillary Clinton, junto a otros senadores, en una iniciativa bipartidista, presionaron para modificar y desarrollar la normativa precisa de cara a fomentar la experimentación con clases single-sex en las escuelas públicas, considerando que este modelo, no sólo favorecería la mejora en el rendimiento académico, sino que además suponía ampliar las opciones de los padres en la elección del modelo educativo que desean para sus hijos $^{73}$.

El apoyo político a la reforma fue prácticamente unánime, como lo expresó la Senadora Susan Collins: "Hace tiempo que era precisa esta reforma (de la Ley federal que promueve los colegios diferenciados por sexo) para corregir la incorrecta interpretación que se ha venido realizando del Título IX de la Ley de 1972... De este modo, se concede a los colegios la flexibilidad que necesitan para diseñar y ofrecer clases single-sex cuando el centro escolar decida que este tipo de docencia separada por sexo concederá a los estudiantes mayores oportunidades para alcanzar objetivos y metas más elevados... " ${ }^{74}$.

Por fin, el 25 de octubre de 2006, se aprobó una norma que desarrollaba la Ley de 2001 con el fin de dotar a los distritos escolares de mayor libertad en la implementación de estos innovadores programas, que cuentan con la asistencia técnica del Gobierno de los EEUU y cuyo coste puede llegar a estar cubierto al $100 \%$ por los recursos federales (incentivos fiscales y otras ayudas económicas $)^{75}$. A cambio, la Administración fijó estrictas metas de rendimien-

${ }^{71}$ K. BAILEY HUTCHISON AND B. MIKULSKI (2012), «A Right to Choose Single-Sex Education», Wall Street Journal, October 17.

72 Public Law 107-110, «No Child Left Behind Act of 2001». Title V —Promoting Informed Parental Choice and Innovative Programs Subpart 3- Local Innovative Education Programs allows and provides for same-gender schools and classrooms. The No Child Left Behind Act of 2001, which reauthorized the Elementary and Secondary Act of 1965. Section 5131(a)(23) of the Elementary and Secondary Education Act.

73 Nondiscrimination on the Basis of Sex in Education Programs or Activities.

Receiving Federal Financial Assistance, 67 Fed. Reg. 31, 097-99 (proposed May 8, 2002) (to be codified at 34 C.F.R. pt. 106).

${ }_{74}$ Congressional Record, June 7, 2001, S5944.

75 Nondiscrimination on the Basis of Sex in Education Programs or Activities.

Receiving Federal Financial Assistance, 71 Fed. Reg. 62,529, 62,530 (Oct. 25, 2006) (to be codified at 34 C.F.R. pt. 106) [hereinafter Single-Sex Rules Final Notice]. Single-Sex Rules Final 
to y rigurosos criterios académicos, realizando cada cinco años un exhaustivo control ex post (National Assessment of Educational Progress); y renovando la autorización únicamente cuando los resultados alcanzados fueran claramente positivos.

Amparados por esta nueva norma, cualquier centro público o que reciba financiación pública, puede transformarse en un colegio diferenciado por sexo o permanecer mixto pero ofreciendo simultáneamente clases single-sex para determinadas asignaturas y edades, siempre y cuando se cumplan los siguientes requisitos:

1. Debe existir un motivo razonable que justifique la implementación del programa de clases single-sex. Por ejemplo, la necesidad de mejoras académicas ante un elevado porcentaje de fracaso escolar o problemas serios de disciplina. Esta motivación deberá guiar la creación del programa «ad hoc» haciendo referencia expresa al curso en el que se aplicará (generalmente se está aplicando en $6^{\circ}, 7^{\circ}$ y $8^{\circ}$ grado); las materias afectadas (normalmente, matemáticas y lengua) y si la oferta se realizará para niños, para niñas o para ambos sexos.

Si la oferta se realizara solo para uno de los sexos, entonces el colegio debe motivar detalladamente por qué y debe demostrar que tiene la capacidad de satisfacer las necesidades educativas del otro sexo por medio de clases mixtas de una calidad similar.

2. El programa debe ser implementado aplicando siempre rigurosos criterios de igualdad en cuanto a los medios y fines en las clases de niños y niñas. Es decir, las expectativas, políticas y procedimientos de promoción y disciplina deberán ser los mismos para ambos sexos.

3. La matrícula en clases single-sex será siempre absolutamente voluntaria. Es una opción educativa a la que los padres podrán adherirse con entera libertad. Para ello, deberán ser previamente informados en profundidad acerca de este modelo y sobre cuáles son los potenciales beneficios de este sistema pedagógico.

4. Los alumnos que no formen parte de un programa de clases single-sex deberán recibir en las aulas mixtas el mismo tipo de educación desde el punto de vista cualitativo. Esto significa que será igual, por lo menos, en cuanto a: los criterios de admisión a la escuela; criterios curriculares; disponibilidad de textos escolares; medios tecnológicos; accesibilidad geográfica; fuentes de formación

Notice, supra note 3; see also Press Release, Dep't of Educ., Sec'y Spellings Announces More Choices in Single Sex Education: Amended Regulations Give Communities More Flexibility to Offer Single Sex Schools and Classes (Oct. 24, 2006), http://www.ed.gov/news/pressreleases/2006/ 10/10242006.html. 
y calificaciones. Sin necesidad, como ha señalado la jurisprudencia, de que sea idéntico ${ }^{76}$.

5. Los colegios que oferten clases single-sex para un único sexo, deberán tomar las medidas adecuadas para ofrecerlas también al sexo opuesto en cualquier momento en que un número razonable de alumnos lo solicite.

6. Cada dos años el colegio, deberá realizar evaluaciones periódicas sobre el cumplimiento de los objetivos que justificaron la implementación del programa.

Las experiencias diferenciadas en centros públicos han crecido considerablemente al amparo de esta Ley que además permite que este tipo de centros, a pesar de ser públicos, puedan recibir financiación adicional, aportaciones económicas y donaciones de entidades y sujetos privados deseosos de apoyar estos proyectos ${ }^{77}$. Gracias a lo cual se han podido abrir varios centros femeninos y masculinos en Bronx, Queens y también en Chicago, Philadelphia, Dallas y Austin, en los que se están alcanzando tasas de éxito escolar antes impensables entre minorías desfavorecidas ${ }^{78}$.

\section{LA EDUCACIÓN DIFERENCIADA. UNA OPCIÓN DE LIBERTAD}

De conformidad con la normativa vigente, como hemos señalado, la matrícula en clases single-sex será siempre absoluta y completamente voluntaria («completely voluntary») para los padres, que podrán adherirse con entera libertad, tras ser previamente informados en profundidad acerca de este modelo pedagógico y sobre cuáles son sus potenciales beneficios ${ }^{79}$. «La legalidad y constitucionalidad de este modelo educativo radica principalmente en que se trata de una opción voluntaria por parte de los padres. De hecho los padres que envian a sus bijos a este tipo de centros lo bacen con pleno convencimiento de que es lo mejor para ellos, aceptando la separación por sexos con entusiasmo» ${ }^{80}$.

Como afirman unánimemente la senadora republicana Bailey Hutchison y la demócrata Mikulski: "La Ley de 2001 no obliga a que los alumnos sean educados en

76 A.N.A. et al. v. Breckinridge County Board of Education (2011).

77 Entre otros muchos, la Fundación Bill Gates; la periodista Oprha Winfrey; la empresa Estee Lauder o Avon, colaboran al sostenimiento económico de los colegios pertenecientes a la Young Women Leadership Academy. Vid. http://www.ywln.org/

78 Sobre los centros femeninos, vid. www.girlfoundation.org.

79 La Equal Educational Opportunities Act, 1974, 20 USC, 1701-1721 (2003) prohíbe expresamente la asignación forzosa de alumnos a escuelas públicas en base al sexo.

80 Washington Post; oct/25/2006. 
programas o colegios single-sex. Simplemente permite a los colegios ofertar este modelo educativo, siempre y cuando las oportunidades sean las mismas para niños y para niñas» ${ }^{81}$.

La imposición del Departamento de Educación, en cumplimiento del Título IX, de que las clases single-sex sean «completamente voluntarias» significa que debe existir por parte de los padres involucrados un inequívoco deseo de participar, manifestado de forma expresa.

En la reciente Sentencia de 29 de agosto de 2012, el Tribunal de Distrito de West Virginia, resolviendo el recurso presentado por la ACLU contra el programa single-sex del colegio público Van Devender Middle School, insistió en la importancia de que los programas single-sex sean absolutamente voluntarios para los padres. Lo que significará que éstos deberán realizar una declaración expresa, un pronunciamiento claro y explícito, que muestre que han optado y elegido libremente este modelo educativo para sus hijos ${ }^{82}$.

El Tribunal entiende que los padres no deben tener la carga de declararse expresamente en contra para ser excluidos de los programas single-sex. Asimismo, su silencio o pasividad no puede en ningún caso entenderse como inclusivo, presumiéndose su deseo de formar parte del programa diferenciado. Antes al contrario, en ausencia de una declaración expresa de deseo de inclusión en el programa single-sex, el estudiante permanecerá en el sistema mixto, que deberá además ofrecer un modelo docente sustancialmente igual al diferenciado (sin entrar el Tribunal a decidir en qué deberá consistir exactamente tal modelo) ${ }^{83}$.

Según el Tribunal, para asegurar que la participación en clases single-sex es completamente voluntaria, el centro escolar deberá notificar a los padres y estudiantes su derecho a optar libremente por las clases diferenciadas o las clases mixtas, y los padres o tutores deberán dar su autorización expresa — preferentemente por escrito — en la que manifiesten con claridad el deseo de que sus hijos participen en las clases single-sex ${ }^{84}$.

Será pues contrario al Título IX de la Ley, entender que todos los padres quedan incluidos en un programa single-sex automáticamente salvo que expresen lo contrario, pues este sistema no cumpliría, según el Tribunal, los estándares

${ }^{81}$ K. BAILEY HUTCHISON AND B. MIKULSKI (2012), «A Right to Choose Single-Sex Education», Wall Street Journal, October 17.

82 JANE DOE v.WOOD COUNTY BOARD OF EDUCATION, CIVIL ACTION NO. 6:12-cv-04355

83 "Lacking that assent, a student must have the "substantially equal" alternative promised by the regulations, although this court declines to define today what that alternative must entail».

84 «Because single-sex classes are, by their very nature, a gender classification, it makes perfect sense to require the parent or guardian's clear and affirmative assent». 
de «completa voluntariedad» de la opción single-sex previstos por la normativa al respecto ${ }^{85}$.

El silencio con efectos inclusivos es efectivo y admisible como sustitutivo de una declaración expresa en algunos supuestos legales, como sucede con las «class actions» (todos los afectados se presumen automáticamente incluidos en la acción salvo que expresen su deseo de ser excluidos ${ }^{86}$ ), pero es absolutamente intolerable en relación con las clases single-sex, pues vulneraría el propósito del Título IX de prevenir las discriminaciones por razón de sexo ${ }^{87}$. Es decir, los padres deben expresar su deseo de participar en el programa single-sex; no su deseo de quedar fuera del mismo (porque se les haya presumido ex ante conformes con tal iniciativa). La ausencia de este requisito se entendería una violación del Título IX.

\section{OPOSICIÓN A LOS COLEGIOS SINGLE-SEX}

La educación diferenciada en EEUU no está exenta de críticas y argumentaciones en contra ${ }^{88}$. Ante los Tribunales, la oposición más fuerte es representada por la ACLU. Esta asociación, en sus recursos, sigue aludiendo de forma reiterada al caso Brown v. Board of Education (1954); considerando que separar por sexo en las escuelas es tan inconstitucional y discriminatorio como separar por raza. Sin embargo, el TS, como ya indicamos, en su Sentencia United States $v$. Virginia (1996) dejó claro que no es así: «El Tribunal Supremo nunca ba mantenido que la separación por sexo en las escuelas públicas - a diferencia de la separación por raza- sea per se inconstitucional... ${ }^{89}$. Muchos años antes, el Juez Powell explicó en Regents of California vs. Bakke (1978), que el Tribunal Supremo nunca ha extendido el rígido escrutinio total de la enmienda decimocuarta a las querellas

85 "An opt-out provision is insufficient to meet the requirement that single-sex classes be "completely voluntary».

86 See, e.g., Phillips Petroleum Co. v. Shutts, 472 U.S. 797, 812 («We reject petitioner's contention that the Due Process Clause of the Fourteenth Amendment requires that absent plaintiffs affirmatively "opt in" to the class, rather than be deemed members of the class if they do not "opt out." ").

87 "A failure to opt out may be a legal substitute for agreement in some other areas of the law, such as membership in class actions... presuming that parents or guardians have enrolled their child in a single-sex class completely voluntarily because they failed to opt out would undermine the purpose of Title IX to prevent discrimination based on gender».

88 Entre los críticos con la educación single-sex, ver, ZADKER, D. \& ZIMMERMAN, K. (2004) Single-Sex Schools: A Good Idea Gone Wrong?, C. SCI.MON. at 9, available at http://www. sadker.org/PDF/SingleSexSchools.pdf. Más reciente: V. BERGER (2012), «Sex-segregated public schools: illegal and unwise. Single-gender education is legally vulnerable on equal protection and other grounds; it is also a regressive social policy». The National Law Journal, January 16.

89 A.N.A. et al. v. Breckinridge County Board of Education (2011) 
sobre discriminación por motivos del sexo porque el Tribunal no ve tal discriminación como «inherentemente odiosa», comparada con la larga y trágica historia de la discriminación racial.

Como señaló la justicia federal en el caso A.N.A. et al. v. Breckinridge County Board of Education (2011): «El término segregar, tal y como ba sido utilizado históricamente, significa causar o forzar la separación de un grupo (como sucedió con la separación racial o por clase social) del resto de la sociedad». Sin embargo, los colegios diferenciados por sexo no «segregan» a sus estudiantes como los demandantes, en concreto la ACLU, pretenden hacer creer de forma reiterada, sino que, por el contrario, conceden a los padres la libre opción de elegir clases single-sex o mixtas para sus hijos ${ }^{90}$.

En otra reciente sentencia del Tribunal de Distrito de West Virginia, de 29 de agosto de 2012, el juez, saliendo al paso de las pretensiones de ACLU de que se considerase inconstitucional y prohibida en todo caso la educación diferenciada en las escuelas públicas y en las financiadas con fondos púbicos, confirmó la legitimidad de este modelo educativo, y recordó que, como ya señaló la jurisprudencia en sentencias anteriores: los programas single-sex, como una opción libre de los padres, en escuelas públicas, no se pueden presumir ipso facto dañinos para los estudiantes; como, sin embargo, sí sucede con la separación por raza.

En palabras de la profesora Salomone, la separación racial no es en absoluto comparable con la diferenciación por sexo, pues ésta es siempre y en cualquier caso voluntaria y querida por los padres, mientras que la segregación por raza que se producía hace décadas en algunos centros escolares era impuesta de manera forzosa y absolutamente en contra de su voluntad ${ }^{91}$.

El Tribunal Supremo en diversas ocasiones se ha opuesto radicalmente a las pretensiones de la ACLU, manteniendo que la diferenciación por sexo en las escuelas es admisible y constitucional en un sistema educativo que pretende favorecer la pluralidad y diversidad de opciones y oportunidades educativas;

90 A.N.A. ex rel. S.F.A. v. Breckinridge Cnty. Bd. of Educ., 833 F. Supp. 2d 673, 678 (W.D. Ky. 2011).

91 SALOMONE, R. (2007), «The Story of the Virginia Military Institute: Negotiating Sameness and Difference», en Education Law Stories, ed. Michael Olivas and Ronna Greff Schneider (Foundation Press). (2007), «Il Dibatto in USA Sulla Single-Sex Schooling», en Maschi e Femmine a Scuola: Le Differenze di Genere in Educazione, ed. Giuseppe Zanniello (Societa Editrice Internazionale). (2007) «Public Single-Sex and Coeducational Schools», en Encyclopedia on Gender and Education, ed. Barbara Bank (Greenwood Press). (2007) «Igualdad y diferencia. La cuestión de la equidad de género en la educación», Rev. Española de Pedagogía, núm. 238, pág. 433, (septiembrediciembre). 
siempre y cuando se cumplan los estrictos requisitos previstos en la regulación de $2006^{92}$.

Además, paradójicamente, la educación separada por sexo ha sido especialmente incentivada por grupos de defensa de los derechos civiles de minorías, que lo consideran un modelo óptimo para superar el déficit educativo histórico de afroamericanos y latinos ${ }^{93}$. De hecho, las experiencias en este sentido, amplia y expresamente apoyadas por el Presidente Obama y el Secretario de Educación Duncan, están dando magníficos resultados que superan todas las expectativas $^{94}$.

Las argumentaciones jurídicas de los detractores de la educación singlesex, basadas en la supuesta segregación o discriminación entre los sexos, que resultaban defendibles en los años 60 y 70, no se sostienen actualmente en unas escuelas diferenciadas que ofrecen los mismos medios, programas y currículums, y pierden toda su base a la luz de los óptimos resultados académicos y personales que este modelo pedagógico está proporcionando, tanto para los niños, como para las niñas ${ }^{95}$, especialmente entre minorías históricamente desfavorecidas ${ }^{96}$.

\section{CONCLUSIÓN. LIBERTAD DE ELECCIÓN DE CENTRO DOCENTE. THE RIGHT TO CHOOSE}

Stephanie Monroe, encargada de la defensa de los derechos civiles en el Departamento de Educación, explica que el apoyo a los colegios e institutos públicos single-sex, se debe en gran parte a la necesidad de que el acceso a este tipo de centros no sea una opción elitista, sólo asumible por familias capaces de pagar un centro privado. Esta posibilidad debe extenderse a toda la población sea cual

${ }_{92}$ See United States $v$. Virginia, 518 U.S. at 533 \& n. 7.

93 En esta línea, Theodore Shaw, presidente hasta 2008 de NAACP Legal Defense and Educational Fund, considera que «la crisis de los chicos varones de color es tan profunda que es preciso experimentar con modelos alternativos como el single-sex».

94 Vid. al respecto, entre otros: www.urbanprep.org. www.eagleny.org

95 Ver. CLARK, C. S. (1994), «Education and Gender.» CQ Researcher, 3 June, 481-504. GLAZER, S. (2005), «Gender and Learning.» CQ Researcher, 20 May, 457-467. MULLINS, A. (2005) «Single' Sex Schools Can Improve Education.» CQ Researcher. 3 Aug.

96 El estudio titulado: Yes We Can, The Schott 50 State Report on Public Education and Black Males, de 2010, realizado por la Schott Foundation for Public Education, señala cómo solo el $47 \%$ de los varones de color logran acabar la educación secundaria obligatoria. Más datos pueden encontrarse en: www.blackboysreport.org 
sea su nivel de ingresos. Si la educación diferenciada está dando buenos resultados ¿por qué reservarla sólo a aquella parte de la población que puede pagarla?

En palabras de la senadora Hutchison: «Estamos intentando ofrecer más opciones a la escuela pública; posibilidades que están disponibles en los centros privados...porque queremos colegios públicos capaces de ofrecer programas que se adapten mejor a las necesidades de los estudiantes en cualquier área. A veces, en ciertas circunstancias, encontramos que tanto las niñas, como los niños, lo hacen mejor en ambientes single-sex... Rompen las barreras... Es necesario abrir estas opciones para los colegios públicos (...) nuestro objetivo a largo plazo es hacer que la educación diferenciada por sexo sea una opción accesible para todos los niños, no solo para aquellos cuyos padres pueden permitirse el lujo de pagar un centro privado» ${ }^{97}$.

Según Salomone, con que solo unos cuantos alumnos salieran beneficiados ya sería una justificación suficiente para ofertar este modelo educativo en igualdad de condiciones a todos, y no solo a aquellas familias con capacidad económica para pagar un centro privado ${ }^{98}$. «La educación diferenciada es un asunto en el que los principios esenciales de la libertad individual (libertad de elección) y la igualdad (en forma de igualdad de oportunidades) son claramente recognoscibles y resultan mutuamente reforzados... Si la igualdad es realmente un objetivo fundamental de la educación pública, entonces los colegios públicos deberían poder permitirse el lujo de superar sus desventajas históricas concediéndoles las mismas oportunidades que históricamente ban tenido los colegios privados (como la de ofrecer clases single-sex)» ${ }^{99}$.

Como señaló William Rehnquist, Juez del Tribunal Supremo de los EEUU, en el caso U.S. v. Virginia (1996), "Son abundantes las pruebas que muestran que la educación diferenciada por sexo es beneficiosa pedagógicamente para algunos estudiantes... esto justificaría suficientemente el empeño de algunos Estados en promover su implantación» ${ }^{100}$.

97 Senadora Kay Bailey Hutchison (R-TX), Congressional Record, June 7, 2001, S5943-S5944

98 SALOMONE, R. (2004), «Feminist voices in the debate over single-sex-schools: finding common ground»; Michigan Journal of Gender and Law, vol II,issue 1.

99 SALOMONE, R. (1999), «Single-Sex Schooling: Law, Policy, and Research» Brookings Papers on Education Policy 1999 (Brookings Institute: Washington, DC), pág. 278. SALOMONE, R. (2007), «The Story of the Virginia Military Institute: Negotiating Sameness and Difference», in Education Law Stories, ed. Michael Olivas and Ronna Greff Schneider (Foundation Press).

${ }^{100}$ Un dato significativo es que algunas de las mujeres norteamericanas que han llegado a lo más alto, a romper lo que allí llaman «el techo de mármol», han estudiando en colegios solo para mujeres. Nancy Pelosi (la primera mujer portavoz de la Casa Blanca), Sally Ride (primera mujer que viajó al espacio), Madeleine Albright (primera mujer Secretaria de Estado), Condoleezza Rice (primera mujer responsable de la Seguridad Nacional y luego también Secretaria de Estado), Drew Gilpin Faust (única mujer Presidente de Harvard), Christine Todd Whitman (primera mujer gobernadora de un Estado), Hillary Clinton (actual Secretaria de Estado), todas ellas tienen 
Si algo es evidente, es que lo que es bueno para los ricos también lo es sin duda alguna para aquellos con menor poder adquisitivo, a los que, en consecuencia, se debe dar esta oportunidad si así lo demandan ${ }^{101}$.

Estamos presenciando la implantación seria y definitiva de un nuevo modelo pedagógico, cuya fuerza arranca de sus propias ventajas, demostradas empíricamente, y de su fuerte aceptación social, al margen de ideologías, creencias o tendencias; lo que ha llevado a republicanos y demócratas a aunar sus esfuerzos en apoyo de la educación diferenciada, en la medida en que supone ampliar las opciones de los padres y conceder una oportunidad a minorías hasta ahora desfavorecidas en el ámbito educativo ${ }^{102}$.

en común haber estudiado en un colegio single-sex. Y podría pensarse que han llegado tan arriba por estudiar en un colegio privado, pero sólo el $7 \%$ de los colegios privados norteamericanos son diferenciados por sexos, lo cual indica que los colegios sólo para mujeres potencian el liderazgo femenino. Esas mujeres no han salido del $93 \%$ de los colegios privados mixtos, sino del $7 \%$ de los que son sólo para chicas.

101 Vid. K. BAILEY HUTCHISON \& B. MIKULSKI (2012), «A Right to Choose SingleSex Education», Wall Street Journal: "No one is arguing that single-sex education is the best option for every student. But it is preferable for some students and families, and no one has the right to deny them an option that may work best for a particular child. Attempts to eliminate single-sex education are equivalent to taking away students' and parents' choice about one of the most fundamentally important aspects of childhood and future indicators of success-a child's education... America once dominated educational attainment among developed countries, but we have fallen disastrously in international rankings. As we seek ways to offer the best education for all our children, in ways that are better tailored to their needs, it seems not just counterproductive but damaging to reduce the options. Single-sex education in public schools will continue to be a voluntary choice for students and their families. To limit or eliminate single-sex education is irresponsible. To take single-sex education away from students who stand to benefit is unforgivable».

102 En otros países también se ha abierto un intenso debate público sobre la eficacia de la educación diferenciada, sus ventajas y desventajas están siendo analizadas en profundidad. Y en muchos de ellos la discusión y el análisis ha dejado ya paso a la adopción de medidas concretas, como la creación de colegios públicos «single-sex» o la separación dentro de un mismo colegio de clases de niños y clases de niñas durante determinadas edades. Como ejemplo, podemos citar el caso de Nueva Gales del Sur, el estado con más población de Australia, donde las solicitudes de plaza en escuelas públicas mixtas se redujo, ya en el 2001, en un 50\% (GREEN, S. 2004, The age, Education Editor; October 11). Otro ejemplo lo encontramos en los Lander alemanes de Berlín y Renania del Norte-Westfalia, donde, desde 1998, por iniciativa de los socialistas y los verdes y con apoyo de los movimientos feministas, después de una seria investigación, se autorizaron las clases diferenciadas por sexo. En la actualidad es usual oír hablar en ámbitos pedagógicos de un nuevo concepto, la «coeducación reflexiva» que sostiene que, durante determinados periodos del desarrollo de los alumnos (especialmente durante la pubertad) o para la enseñanza de determinadas materias, conviene establecer clases divididas por sexos, que ahorran además los problemas que se presentan adicionalmente en clases coeducativas como consecuencia de la atracción entre sexos a esas edades. El Instituto Pedagógico de Kiel realizó un estudio en Berlín, Hamburgo y la Baja Sajonia y, apoyándose en los resultados académicos obtenidos, demostraba que cuando 
La clave del éxito de la educación diferenciada, afirman los expertos, radica en el equilibrio entre el reconocimiento de la diferencia y la garantía de la igualdad de oportunidades entre sexos ${ }^{103}$.

La educación separada por sexo es una magnífica opción pedagógica y educativa. Pero no es la única opción válida, como tampoco debería serlo la educación

alumnos y alumnas eran separados para recibir enseñanza en determinadas materias, tanto el interés como las calificaciones mejoraban de forma significativa. En Gran Bretaña, la red escolar está formada por centros masculinos, femeninos y mixtos con la misma consideración. Como es sobradamente conocido, los más prestigiosos colegios son diferenciados. Existe en este país una tradición arraigada de este tipo de escuelas. Al respecto es destacable el estudio realizado por la International Organization for the Development of Freedom Education (OIDEL), éste concluye que entre las primeras 50 mejores escuelas del Reino Unido, 36 son diferenciadas. Aún así, en diciembre de 2004 el Ministro David Miliband (School Standards Minister), declaró la necesidad de insistir en los beneficios derivados para los jóvenes de una educación en colegios diferenciados. Esta insistencia partió de la reciente publicación de un informe, resultado de cuatro años de investigación, de la Facultad de Educación de la Universidad de Cambridge, en el que se analizaban pormenorizadamente los beneficios que resultan de la educación diferenciada frente al sistema de educación mixta. En Francia, la educación mixta comenzó a cuestionarse seriamente a partir de la publicación del controvertido libro del sociólogo (especialista en temas de adolescencia, juventud y familia) Michel Fize (2003), Las trampas de la educación mixta, donde expone cómo la educación mixta en el país galo no ha conseguido asegurar la igualdad de oportunidades ni de sexos. En Québec, el prestigioso Consejo Superior de la Educación, en un informe de 1998, estimó necesaria una radical reforma pedagógica encaminada a separar chicas y chicos en las escuelas. Medida que de hecho ya se está aplicando. En Suiza, el debate se reabrió en 1993 a raíz de una Conferencia de Directores Cantonales de Educación. En las conclusiones finales se proponía que, para eliminar los estereotipos y atender mejor a las necesidades de las chicas, era preciso adoptar las medias que fueran necesarias, incluyendo la separación de sexos, con el fin de lograr una enseñanza individualizada y diferenciada. En Nueva Zelanda, el Ministro de Educación, recientemente, ha creado un «think tank» para investigar las razones por las que los niños obtienen bastante peores calificaciones que las niñas en secundaria. Todo parece indicar que el menor rendimiento académico de los varones está íntimamente relacionado con el sistema de clases mixtas (The New Zealand Herald; abril 2005). En Escocia, las estadísticas del gobierno demuestran que el $55 \%$ de las chicas de menos de 21 años accedieron a la educación superior el año 2002-03, mientras que sólo el 42\% de los chicos lo hicieron. El primer ministro de Escocia, Jack McConnell, ha decidido experimentar con clases de un solo sexo (Scotsman; 14/9/04). En Suecia, en julio de 2004, la parlamentaria Chris Heister, presidenta de la Comisión para el Estudio de la Educación, publicó un informe con el título: «Todos somos diferentes». Este estudio considera como principal causa del fracaso escolar el empeño por despreciar las diferencias entre sexos. «Se ha demostrado que las niñas entre los 7 y 15 años, asimilan con más rapidez que los niños. Mientras que en la secundaria, tienen mayores dificultades que los chicos. Por otra parte, hay que tener en cuenta que las chicas alcanzan la madurez mucho antes que los chicos, y aunque tengan la misma edad no se les puede tratar igual». El informe finaliza recomendando clases diferenciadas, «porque no es lícito imponer conductas o modelos idénticos a ambos sexos».

103 Vid. al respecto, GURIAN, M. (2006), «Learning and gender», American School Board Journal.

(C) UNED. Revista de Derecho Politico 
mixta. Ningún modelo es perfecto para todos los alumnos ${ }^{104}$. La diversidad y la pluralidad de modelos educativos es la fuerza que vertebra la verdadera libertad de enseñanza. Es obligación de los poderes públicos hacer posibles todas las ofertas educativas y dar a quien lo desee la oportunidad de realizar al máximo sus posibilidades dentro de la opción libremente escogida. Siempre constituirá un enriquecimiento para la oferta educativa poder contar con el mayor número de opciones posibles. Cada familia debería poder ver satisfechas sus preferencias con independencia de su nivel económico. Lo importante es que exista la posibilidad de decidir un sistema u otro con entera libertad. Se trata de debatir sobre qué es lo mejor para nuestros hijos, dar información a los padres y concederles el derecho de elegir libremente una de las opciones. Está en cuestión la propia libertad de educación. Una sociedad plural y democrática exige asimismo una pluralidad de opciones educativas. La Administración no solo no puede decidir por ellos, sino que, por el contrario, tiene la obligación de favorecer el ejercicio de este derecho por parte de los padres, abriendo el abanico de opciones educativas al máximo posible ${ }^{105}$.

En 2007, el Departamento de Educación de los EEUU, en un minucioso estudio, tras la consideración de las 40 mejores investigaciones realizadas, seleccionadas entre 2000 investigaciones que comparaban la educación diferenciada y la mixta, llegaba a la siguiente conclusion: «La educación diferenciada por sexo es una práctica educativa muy prometedora... Tenemos razones de peso para concluir que la educación single-sex ayudará a mejorar los resultados académicos de los alumnos en los EEUU» ${ }^{106}$.

104 GUARISCO,C.(2010), «Single-sex schools and gender roles: barrier or breakthrough?», May 19. (http://www.luc.edu/law/archive/child/childed_forum/pdfs/2010_student_papers/Chrissy_Guarisco.pdf); PIATT, B. (2009), «Gender Segregation in the Public Schools; Opportunity, Inequality, or Both», 11 SCHOLAR 561, 575.

105 Convención de las Naciones Unidas de los Derechos del Menor. Artículo 18.1: «... Incumbirá a los padres, o en su caso, a los representantes legales la responsabilidad primordial de la crianza y el desarrollo del niño. Su preocupación fundamental será el interés superior del niño».

${ }^{106}$ Final Report of the US Department of Education's systematic review of research, 2007. 
Title:

SINGLE-SEX EDUCATION IN THE UNITED STATES: CONSTITUTIONALITY AND CURRENT DEVELOPMENTS OF AN UNSTOPPABLE TREND

\title{
Summary:
}

I. Introduction. II. Historical reference and timeliness of single-sex education in the U.S. III. Constitutionality and legality of single sex education. 1. Do the single-sex schools discriminate by gender? Amendment XIV to the U.S. Constitution: «Equal protection clause». a) Race segregation at school; b) Gender segregation at school; 2. Legality of single-sex education. Title IX and No child Bebind Act. IV. Single-sex educaction. An option for freedom. V. Against single sex education. VI. Conclusion. The right to choose.

\section{Resumen:}

En los últimos años Estados Unidos ha experimentado el resurgir de la educación diferenciada por sexo con el apoyo de políticos de muy diferentes tendencias, educadores, padres, ciertos sectores feministas, así como asociaciones de defensa de los derechos de los afroamericanos y otras minorías. Esta tendencia, lenta pero implacable, entre los colegios públicos, como consecuencia de los excelentes resultados obtenidos, ha generado un encendido debate en ámbitos académicos, legales y políticos.

La legislación norteamericana federal los motiva, incentiva y apoya, con ciertas condiciones relativas a garantizar la igualdad de oportunidades entre los sexos y la libertad de elección de los padres del modelo educativo que consideren apropiado para sus hijos. No obstante, la American Civil Liberties Union sigue mostrando su abierta oposición a estos centros educativos a los que considera discriminatorios. En este marco, hasta el momento, el Tribunal Supremo no ha encontrado en estos centros tacha alguna de inconstitucionalidad.

\begin{abstract}
:
In recent years the U.S. has experienced a resurgence of single-sex education with the support of politicians of very different tendencies, educators, parents, some feminist sectors and associations defending the rights of African Americans and other minorities. This trend, slowly but relentlessly, including public schools, has generated a heated debate in academic, legal and political fields. The federal U.S. legislation motivates, encourages and supports, with certain condi-
\end{abstract}


tions relating to ensuring equality of opportunity between the sexes and freedom of parental choice of educational model they consider appropriate for their children. However, the American Civil Liberties Union continues to show his outspoken opposition to these schools to which they considered discriminatory. In this framework, so far, the Supreme Court has found these centers absolutely constitutional.

\section{Palabras clave:}

Educación; igualdad; libertad de elección; diferencias por sexo; feminismo; discriminación.

\section{Key words:}

Education, equality, freedom of choice, gender differences, feminism; discrimination. 